\title{
Serbian pitch accents in tri-syllables produced by Serbian and Russian speakers
}

Ekaterina Panova

Dept of history and theory of language, St. Tikhon's Orthodox University, Russia

https://doi.org/10.36505/ExLing-2016/07/0030/000289

\begin{abstract}
This study is based on the analysis of tri-syllables in initial, medial and final position of statements. For each syllable of the tri-syllables the set of pitch parameters was calculated, as well as F0 inter-syllable intervals. In FA pitch parameters reach maximum values on first syllables and in RA - on second ones. FA and RA more differ in initial than medial position and tend to neutralization in final position. In initial and medial position Russian speakers realize a "type of accent" that is similar to Serbian RA and in final position a "type of accent" that similar to Serbian FA.

Key words: pitch parameters, pitch accent, Russian, Serbian, tri-syllable.
\end{abstract}

\section{Introduction}

Traditionally, Serbian stress is characterised by two contrasts - pitch (falling/rising) and duration (long/short) that make four combinations: long rising (LR), long falling (LF), short rising (SR) and short falling (SF). Nevertheless, such clear classification of Serbian pitch accents, formed by the end of XIX century, has been revealing many discussions (see Lehiste, Ivic 1986, Keijsper 1987, Jokanovic-Mihajlov 2006). The main problems are concerned the distinctive parameters of falling (FA) and rising accents (RA). Recent investigations confirmed that standard Serbian pitch contrasts realized on the sequence of stress and post-tonic syllable(s): negative intervals between stress and post-tonic syllable are typical for FA, while positive intervals for RA; FA have early peak locations, while RA late ones. Our studies (Panova 2015, Panova 2016) supported these previous investigations and revealed that in di-syllables post-tonic syllable provided better FA/RA distinction than stressed one. The parameter of peak location (i.e. timing of $\mathrm{F} 0$ maximum) can provide FA/RA distinction only with respect to the pitch contour of the whole word, but not only with respect to stressed syllable. Russian speakers had difficulties in the production of FA/RA Serbian contrast: in non-final position of the statements they produced "types of accents" that were similar to Serbian RA.

ExLing 2016: Proceedings of $7^{\text {th }}$ Tutorial and Research Workshop on Experimental Linguistics, 27 June - 2 July 2016, Saint Petersburg, Russia 


\section{Method}

For the present study 42 words of tri-syllables with stress on the first syllable and different types of accents were selected. Each target trisyllable word was embedded in frame statements so as to occur in initial and medial position (42*3). Two native speakers of Serbian (S1, S2, females) and four Russian speakers (R1, R2, R3, R4, females) read the sentences in neutral style and normal tempo.

For both Serbian and Russian samples we calculated F0 contour and obtained following pitch parameters (Smirnova et al. 2007) for each syllable of the tri-syllables: F0 start value, F0 end value, F0 maximum, F0 minimum, F0 mean value, $\mathrm{F} 0$ range and timing of $\mathrm{F} 0$ maximum (time point of F0 maximum measured in \% of the total syllable duration). For each tri-syllable word we also obtained values of two F0 inter-syllable intervals between first and second syllable and between second and third one.

For the statistical analysis an ANOVA repeated measures was performed separately for Serbian and Russian speakers and for initial, medial and final position of the statements. For the first six pitch parameters we investigated effects between independent variables ACCENT (LF, LR, SF and SR), and SYLLABLE (1, 2, 3). For the F0 inter-syllable interval we investigated INTERVAL (1 vs. 2) and ACCENT (LF, LR, SF and SR). More detailed statistical analysis was provided by post Tukey HSD tests. For the analysis of timing of F0 maximum we used Survival Analysis with ACCENT (LF, LR, SF and $\mathrm{SR})$ as a grouping variable.

\section{Results}

The results for Serbian speakers showed that the main effects of SYLLABLE and ACCENT as well as interaction between SYLLABLE and ACCENT were highly significant $(\mathrm{p}<0.0001)$ for $\mathrm{F} 0$ start value, F0 end value, F0 maximum, F0 minimum, F0 mean value in initial and medial position (in Figure 1 we give an example of F0 start values). For all these pitch parameters we can obtain the same tendencies: FA reach maximum values on first syllables, second and third syllables demonstrate gradual decrease, while RA reach minimum values on first syllable (for F0 end value on third syllable) and maximum values on second syllable. Post hoc test showed that regarding these pitch parameters Serbian four accents divided mostly on two types: falling (LF and SF) and rising (LR and SR), within these types there is not any significant difference. At the same time Serbian accents differ more clearly in initial than in medial position, where the distinction between 
FA and RA is broken, because SF values in second syllable approach to the values of RA. Regarding syllables Serbian accents differ more in first and second syllables than in third ones.

In final position the results of these pitch parameters didn't show any significance regarding the main effect ACCENT, although the effect of SYLLABLE and interaction between ACCENT and SYLLABLE were significant $(\mathrm{p}<0.001)$.

The results for F0 range and timing of F0 maximum for Serbian speakers were not significant in all positions.
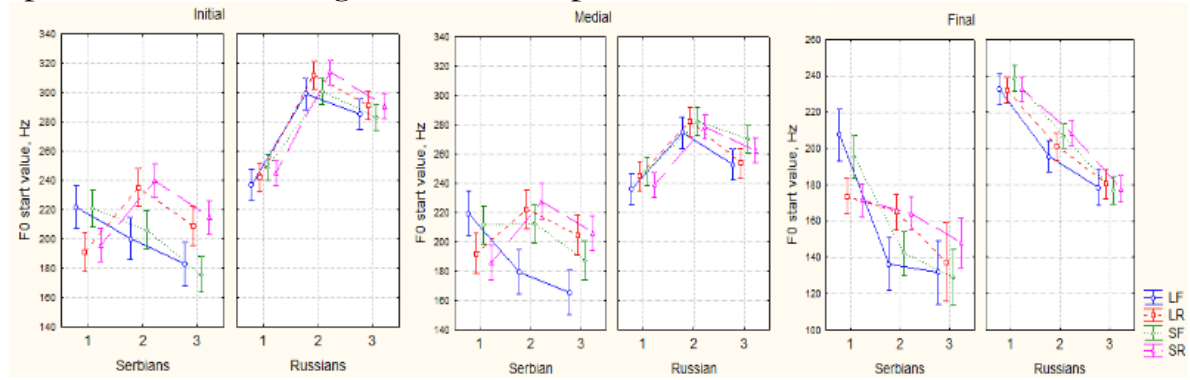

Figure 1. F0 start value scores of the first (1), second (2) and third (3) syllables with LF, LR, SF and SR for Serbian and Russian speakers in initial, medial and final position.

For Russian speakers the main effect of ACCENT was not significant regarding all pitch parameters except for marginally significant results for F0 start value $(\mathrm{p}=0.043)$ and $\mathrm{F} 0$ maximum $(\mathrm{p}=0.047)$ in final position. However, for Russian speakers the main effect of SYLLABLE was highly significant $(\mathrm{p}<0.0001)$ for all the parameters in all positions except for F0 range. As we can see from Figures 1, in initial and medial position the values of pitch parameters for Russian speakers are similar to Serbian RA: maximum values are reached on second syllable, while minimum values are on first one. In final position, on the contrary, the values of pitch parameters for Russian speakers are similar to FA.
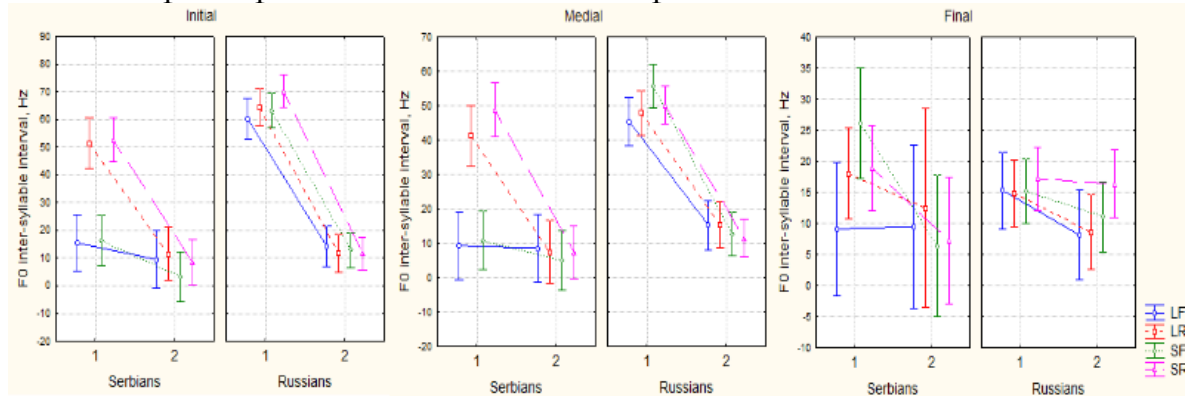

Figure 2. F0 inter-syllable interval scores between first and second (1) and second and third (2) syllables with LF, LR, SF and SR for Serbian and Russian speakers in initial, medial and final position. 
The analysis of F0 inter-syllable interval revealed that for Serbian speakers in initial and medial position there is a significant difference between FA and RA only in interval between first and second syllable, while interval between second and third syllable is not significant for FA/RA distinction (see Figure 2). FA have smaller intervals between first and second syllable than RA. For Russian speakers the values of interval between first and second syllable are similar to Serbian RA.

\section{Conclusion}

The results of pitch parameters of the tri-syllables produced by Serbian speakers showed that FA/RA distinction is provided on all three syllables, although first and second syllables are more significant than third one. For FA the pitch parameters (F0 start value, F0 end value, F0 maximum, F0 minimum, F0 mean value) reach maximum values on first syllables and minimum values on third one, while for RA pitch parameters reach maximum values on second syllables and minimum on first ones (except for F0 end value). The FA/RA contrast realizes more clear in initial, than medial position and in final position tends to FA/RA neutralization. In medial position the values of pitch parameters of the second syllable for SF approach to the values for RA, that correspond with the fact about tonal prominence of SF (Lehiste, Ivic 1986). FA/RA contrast can also be observed on the different F0 inter-syllable intervals between first and second syllable: RA have larger intervals than FA. The values of F0 range and timing of F0 maximum didn't demonstrate any FA/RA distinctive ability.

Regarding analyzed pitch parameters Russian speakers realize a "type of accent" that is similar to Serbian RA in initial and medial position and a "type of accent" that similar to Serbian FA in final position.

\section{References}

Jokanovic-Mihajlov J. 2006. Akcenat i intonacija govora na radiju i televiziji. Beograd.

Keijsper, C.E 1987. Studing Neoštokavian Serbocroation Prosody. Dutch Studies in South Slavic and Balkan Linguistics. SSGI 10, 101-193.

Lehiste I., Ivic P. 1986. Word and sentence prosody in Serbocroatian. Cambridge, Mass., MIT Press.

Panova E. Realization of Serbian accents by Serbian and Russian speakers (analysis of pitch parameters). Proc. International Conference of Experimental Linguistics ExLing 2015, 26-27 June 2015, Athens, Greece, 58-61

Panova E. L1 and L2 Serbian accents: Analysis of Pitch Parameters. Proceedings of the Speech Prosody 2016, May 31 - June 3, 2016, Boston, MA, USA, 474-478.

Smirnova, N., Starshinov A., Oparin I. \& Goloshchapova T. 2007. Speaker Identification Using selective Comparison of Pitch Contour Parameters. Proc. 16th ICPhS, Saarbrucken, 203-206. 